\author{
Jerzy Boryczka \\ Department of Climatology \\ E-mail: jkborycz@uw.edu.pl
}

\title{
WARMING AND COOLING OF THE EARTH'S CLIMATE AND THEIR CAUSES
}

\begin{abstract}
The progressing warming of the Earth's climate is mainly caused by natural factors, that is, the increasing solar activity and the decreasing volcanic activity on the Earth. The aspects which testify to the predominance of natural factors include: synchronous changes in the average air temperature in the Northern Hemisphere in the years 1856-2002, the average consecutive 11-year Wolf numbers and the location of the mass centres of the four largest planets.

Natural causes of the climate warming are corroborated by the synchronicity of changes in the carbon dioxide concentration and paleotemperature in the last 450,000 years, revealed on the basis of an analysis of the ice core in Antarctica. Periods of climate warming occur every 100,000 years and are caused by an increased solar radiation in high latitudes, resulting from changes in the Earth's orbit and the inclination of the Earth axis (according to the popular Milankovič theory).
\end{abstract}

Key words: solar radiation, temperature, greenhouse effect, spectrum, solar activity, mass moments of planets.

\section{INTRODUCTION}

In the recent years, publications discussing climate change have disseminated information on the hazards to life on the Earth posed by the increasing carbon dioxide emission to the atmosphere, that is, from the intensification of the greenhouse effect, which may in consequence lead to an excessive global warming.

Changes in the temperature of the Earth (and air, $\Delta T$ ) depend on the difference in the intensity of short-wave solar radiation absorbed by the Earth $(\alpha I \downarrow)$, long-wave earth radiation $(\beta J \uparrow)$ and on the reflection (albedo) and absorption capacity of the Earth's atmosphere and surface $\left(\alpha=\alpha_{a}+\alpha_{2} \beta\right)$ :

$$
c \Delta T=\alpha \mathrm{I} \downarrow-\beta J \uparrow,
$$

The Earth's climate depends mainly on the changes in the short-wave radiation emitted by the Sun $(I \downarrow)$, the atmosphere's absorption capacity re- 
lating to short-wave solar radiation $\left(\alpha_{a}\right)$ and long-wave radiation of the Earth (fraction $\beta$ ).

The so-called greenhouse gases play a large role in shaping the Earth's climate: water vapour $\left(\mathrm{H}_{2} \mathrm{O}\right)$, carbon dioxide $\left(\mathrm{CO}_{2}\right)$ and methane $\left(\mathrm{CH}_{4}\right)$, which can be found in the atmosphere. They are relatively transparent for the incoming solar radiation, but they absorb long-wave radiation emitted by the Earth upwards $(\beta)$. This difference in radiaticn leads to a positive energy balance in the relation between the Earth and the atmosphere, commonly known as the greenhouse effect.

Owing to the existence of the atmosphere and its natural greenhouse effect - the average temperature on the Earth's surface (and of the air) is $+15^{\circ} \mathrm{C}$, and not $-18^{\circ} \mathrm{C}$ - that is, it is by $+33^{\circ} \mathrm{C}$ higher. However, the problem lies in additional anthropogenic emission of those gases to the atmosphere and a systematic increase in their concentration, mainly of $\mathrm{CO}_{2}$ and $\mathrm{CH}_{4}$.

In the last decade of the $20^{\text {th }}$ century, the annual $\mathrm{CO}_{2}$ emission totalled approximately $29 \mathrm{Gt}$ (about $8 \mathrm{Gt}$ of $\mathrm{C}^{12}$ coal), and the emission of methane, the second major greenhouse gas, neared $300 \mathrm{Mt}$. The pre-industrial $\mathrm{CO}_{2}$ concentration of $280 \mathrm{ppm}$ is usually treated as the natural carbon dioxide content in the atmosphere. The difference between the contemporary atmospheric $\mathrm{CO}_{2}$ concentration $(355 \mathrm{ppm})$ and the pre-industrial concentration $(75 \mathrm{ppm})$ is attributed to man's economic activity.

The global warming of the 20th century is mainly ascribed to the anthropogenic aspect of the greenhouse effect - the increase in the carbon dioxide $\left(\mathrm{CO}_{2}\right)$ content, a product of coal combustion. Such conclusions can be derived from the models of general atmospheric circulation - the $2 \times \mathrm{CO}_{2}$ scenarios, following the doubling of the pre-industrial carbon dioxide atmospheric content, $280 \mathrm{ppm}$ (IPCC , 1990, 1995). At the same time, the tendencies in the changes of the main natural greenhouse gas - water vapour - and clouds determining the supply of solar energy to the Earth's surface, are not well known.

A closer look into those tendencies reveals that the contemporary warming and cooling phases of the Earth's climate are strongly correlated with the maximum and minimum values of the measured $\mathrm{CO}_{2}$ mass in the atmosphere, and weakly correlated with the $\mathrm{CO}_{2}$ emission, assessed on the basis of the quantity of combusted coal.

The oceans, which cover 70 per cent of the Earth's surface, are natural water bodies regulating carbon dioxide content in the atmosphere. $\mathrm{CO}_{2}$ absorption by cooler waters (with a larger biomass content) is higher than by warmer waters. When the $\mathrm{CO}_{2}$ content in the atmosphere is higher, the oceans absorb more carbon dioxide, owing to a higher difference in the pressure of this gas between the atmosphere and the oceans' surface. Some of the carbon dioxide is accumulated in the sea bottom deposits as calcium carbonate, $\mathrm{CaCO}_{3}$.

Another significant "regulator" of the carbon dioxide content in the atmosphere is the continental biomass (mainly forests). Photosynthesis (combining $\mathrm{CO}_{2}$ with water $\mathrm{H}_{2} \mathrm{O}$ ) fixes approximately $8 \mathrm{Gt}$ of $\mathrm{CO}_{2}$ per annum, that is, about the annual global output of $\mathrm{CO}_{2}$. 
Also, physical processes accompanying the greenhouse effect, i.e. feedback mechanisms, play a substantial part in determining the Earth's climate. Some of them tend to intensify the greenhouse effect (e.g. strong evaporation, albedo decrease or shrinking of the snow and ice areas), while others (such as the thickness of the clouds' layer mainly in the equatorial zone, concentration of dust absorbing solar radiation) weaken its intensity.

In the $19^{\text {th }}$ and $20^{\text {th }}$ century, the Earth's climate became progressively warmer. In the years 1861-1991, the increase in the average global temperature, calculated on the basis of the measurements of air and water surface temperature was $0.5^{\circ} \mathrm{C}$ on the average.

As the average global air temperature increases, the level of the oceans is rising. The Baltic Sea level, according to the water level in Swinoujście in the years 1811-1990, rises on average by $4.5 \mathrm{~cm}$ per every 100 years (Kożuchowski, Boryczka, 1977). The rising of the water level in the seas and oceans in the $19^{\text {th }}$ and $20^{\text {th }}$ century was partly caused by the cubical expansion of water. Currently, the volume of the oceans' water (excluding the seas) totals 1370.4 million $\mathrm{km}^{2}$, and their average depth $-3704 \mathrm{~m}$. The increase of water temperature by $1^{\circ} \mathrm{C}$ (from 4 to $5^{\circ} \mathrm{C}$ ) corresponds to the increase in the oceans' level by $18 \mathrm{~cm}$.

\section{THE REGRESSION SINUSOID" METHOD FOR DETERMINING SPECTRUMS AND CYCLES}

The "regression sinusoid" method developed by Jerzy Boryczka (1998) consists in adjusting the results of the $y_{1}, \ldots, y_{n}$ measurements performed in time $t_{1}, \ldots, t_{n}$ (using the smallest square values) of consecutive sinusoids with presumed cycles, e.g. $\Theta=1,2, \ldots, n$ (or $0.1 ; 0.2 ; \ldots ; n$ ). the regression sinusoid equation (as termed by the author) with the cycle $\Theta$, amplitude $b$ and phase $c$ :

$$
y=a+b \sin (\omega t+c), \quad \omega=2 \pi / \Theta
$$

is determined by reducing the equation to the linear regression $y$ with respect to the variables $x_{1}=\sin \omega t, x_{2}=\cos \omega t: y=a_{0}+a_{1} x_{1}+a_{2} x_{2}$

Amplitude $b$ and phase $c$ is obtained from a reverse transformation: $b=\left(a_{1}{ }^{2}+a_{2}{ }^{2}\right)^{0,5} \operatorname{tg} c=a_{2} / a_{1}$ (taking into account the conditions $a_{1}=b \cos c, a_{2}=b \sin c$ ).

The spectrum is a sequence of the values of residual variance $\varepsilon^{2}$, corresponding to the presumed cycles $\Theta=0.1 ; 0.2 ; \ldots ; n$. The cycles denote the local minimums $\Theta_{\min }$ of the residual variance $\varepsilon^{2}{ }_{\min }$

This method can be applied when the time intervals between the terms of the chronological sequence are not the same (for example in the case of volcanic eruptions). The result (interference):

$$
y=a_{0}+\Sigma_{j} b_{j} \sin \left(2 \Pi t / \Theta_{j}+c_{j}\right)
$$

of several statistically meaningful cycles (at a meaningfulness level of 0.05 ) explains a large part of the variable variance $y$. The amplitude of the $b$ cycle is verified in the same way as the determination coefficient $R^{2}$, by using 
the Fisher-Snedecor test $\mathrm{F}$, with $n_{1}=2$ and $n_{2}=n-3$ freedom levels or the t-Student test.

The spectra of solar activity based on the data from 1700-2002 and 17492002 can serve as exemplary applications of the "regression sinusoid" method (Fig. 1).

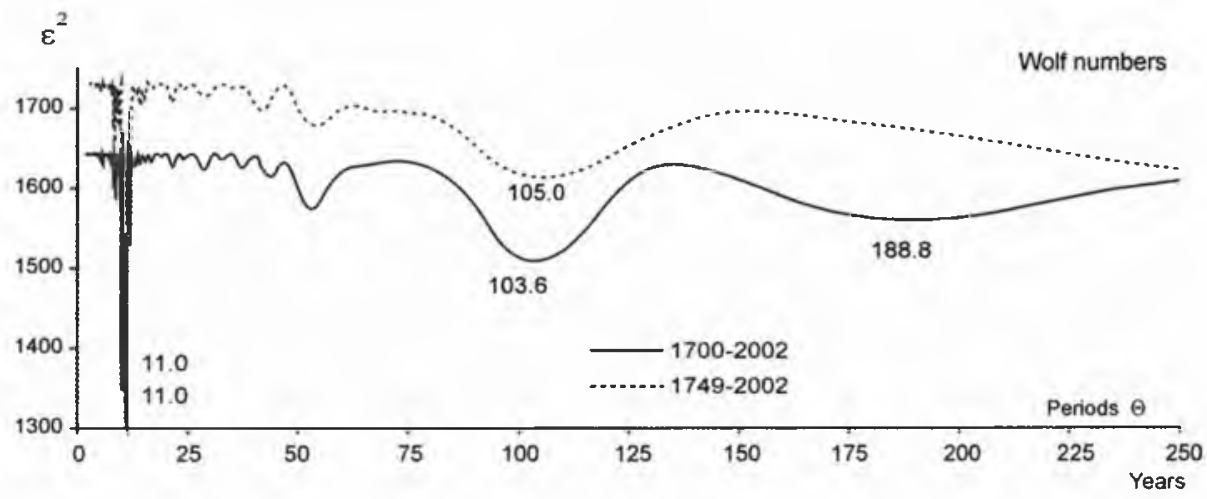

Fig. 1. The spectra of Wolf numbers based on the data from 1700-2002 and 1749-2002 in the range of 2.0-250 years with an interval $\Delta \Theta=0.1$ year

\section{THE IMPACT OF SOLAR ACTIVITY ON THE EARTH'S CLIMATE}

In the 11-year cycle of solar activity, the solar constant changes. It is the highest in the vicinity of the maximums of sunspots (Kondratiev and Nikolski, 1970). Short-term changes in the solar activity do not significantly influence the Earth's climate due to a very slow penetration of heat to the deeper layers of the Earth. Long solar activity cycles play a much more important role (Boryczka, 1998) - the 102-year and the 187-year cycle. In the vicinity of their maximums, large quantities of energy are accumulated in the deeper layers of the continents and the oceans, which affects the overall atmospheric circulation.

The upwards tendency in the activity of the Sun (intensity of radiation) during the last two centuries may be largely responsible for the progressing warming of the Earth's climate owing to changes in the overall atmospheric circulation. This is corroborated by similar simple regressions of the standardised values of the Wolf numbers and the air temperature in Warsaw in the years 1779-2000: $W^{P}=0.0037 t-6.956, T=0.0047 t-8.940$ (Fig. 2)

Synchronous changes in the average air temperature in the Northern Hemisphere in the years 1856-2002 (Bernes, 2003) and the average consecutive 11-year cycle Wolf numbers (Fig. 3) testify to the significant role that solar activity plays in the shaping of the Earth's climate. 


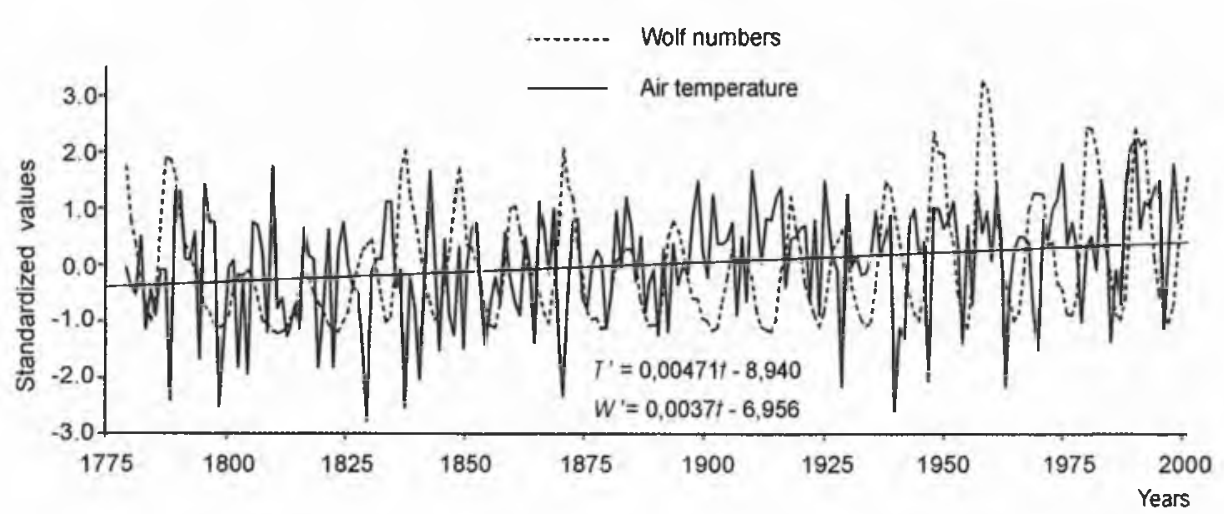

Fig. 2. Similar equations of simple Wolf number regressions and the air temperature in Warsaw in 1779-2000 (standardised values)

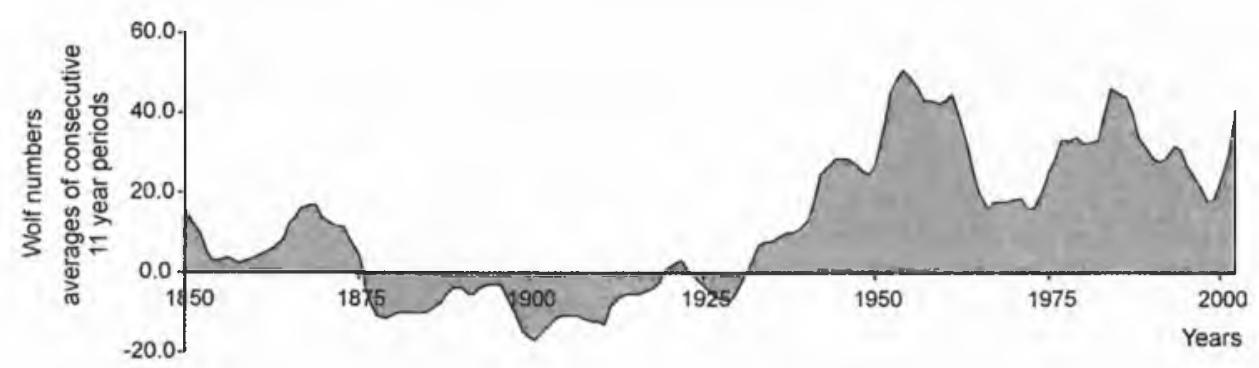

Fig. 3. Changes in solar activity (Wolf numbers) in 1856-2002 (deviations from the average value for the years $1856-1900$ )

Deviations from the average air temperature in the Northern Hemisphere in the years 1856-1900 until 1920 are as a rule negative, and after 1920 positive. The years 1920-2002 are characterised by a significant warming, with the local minimum in the 1970s. The situation is similar in the case of average consecutive deviations relating to the Wolf numbers for 11-year cycles from the average value for 1856-1900. They are negative until 1925, and positive after 1925. The main local minimum of the temperature in the 1970 s (Fig. 3) is matched by the main local minimum for the Wolf numbers; the solar activity in 1925-2002 is also significantly greater than before 1925 .

\section{RELATION BETWEEN SOLAR ACTIVITY AND THE MASS MOMENTS OF THE FOUR LARGEST PLANETS}

Demonstrating the interrelationship between the solar activity (Wolf numbers) and the changes in the location of the centres of the mass of the four largest planets, Jupiter, Saturn, Uranus, Neptune) is of key importance in exploring the reasons behind climatic changes on the Earth (Boryczka, 2003). The concept of exploring the nature of this correlation is 
to describe, mathematically, the physical interactions (which are not known as yet) between the Sun and the individual planets, whose revolution cycles are: $11.862,29.458,84.015$ and 164.79 years. These interactions may be described by identifying the role of the individual planets in the variability of the mass moment $M=\Sigma m_{i} r_{i}$, i.e. in the changes of the location of the centre of the mass of the Solar System, around which the Sun revolves. The modulation of the influence of the nearer planets by the farther ones - with longer revolution cycles - on the Sun was taken into account.

The physical (and not statistical) model is original; it accurately captures the changes in solar activity (Wolf numbers) in the years 1700 2002:

$w=\sin \left(2 \pi t / 11.862+c_{\mathrm{J}}\right)\left(1+M_{12} \sin \left(2 \pi t / 29.458+c_{\mathrm{s}}\right)+M_{13} \sin \left(2 \pi t / 84.015+c_{\mathrm{v}}\right)+\right.$ $M_{14} \sin \left(2 \pi t / 164.79+c_{\mathrm{N}}\right)+M_{12} \sin \left(2 \pi t / 29.458+c_{\mathrm{S}}\right)\left(1+M_{23} \sin \left(2 \mathrm{pt} / 84.015+c_{\mathrm{U}}\right)\right.$ $\left.+M_{24} \sin \left(2 \pi t / 164.79+c_{N}\right)\right)+M_{13} \sin \left(2 \pi t / 84.015+c_{\mathrm{U}}\right)\left(1+M_{34} \sin \left(2 \pi t / 164.79+c_{\mathrm{N}}\right)+M_{14}\right.$ $\sin \left(2 \pi t / 164.79+c_{\mathrm{N}}\right)$

where the relative mass moments of the individual planets are expressed by the matrix $M_{\mathrm{ij}}$ :

\begin{tabular}{|l|l|l|l|l|}
\hline & Jupiter & Saturn & Uranus & Neptune \\
\hline Jupiter & 1 & 0.549629 & 0.168967 & 0.314122 \\
Safum & & 1 & 0.30742 & 0.571516 \\
Uranus & & & 1 & 1.859073 \\
Neptune & & & & 1 \\
\hline
\end{tabular}

The phase displacements of periodic changes in the mass moments of the successive planets, determined using Boryczka's "regression sinusoid" method

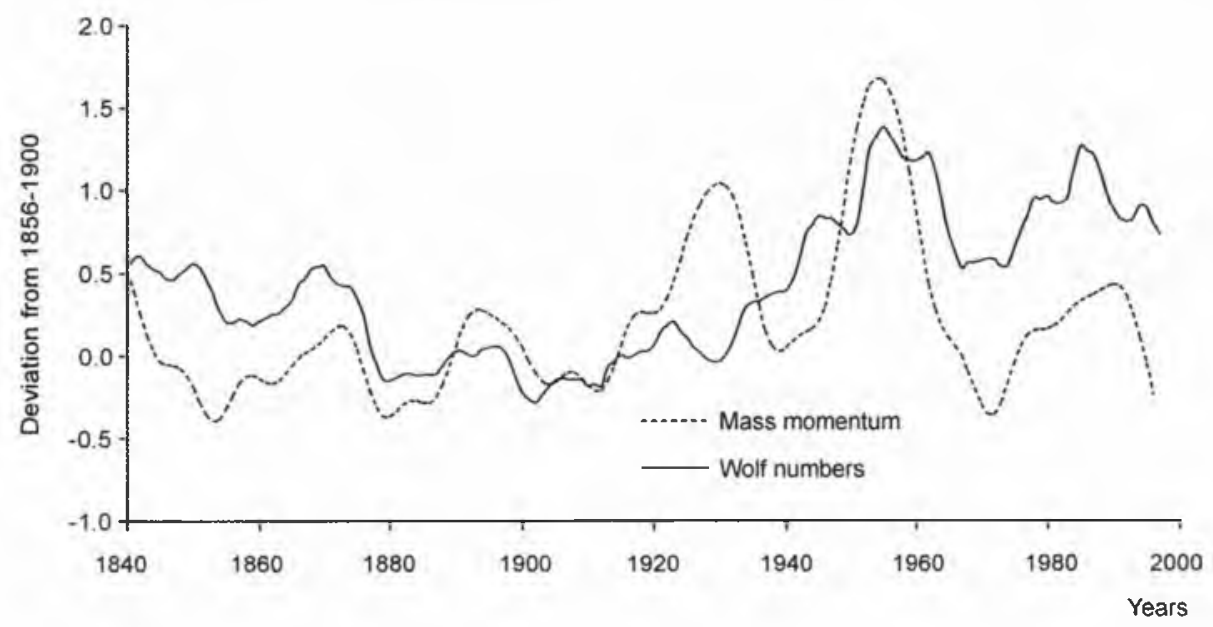

Fig. 4. Changes in solar activity (standardised Wolf numbers) and distance of the mass centres (mass moments) of the largest planers in 1856-2002 (average consecutive values for 11-year cycles). 
(1998), have the following values: $c_{\mathrm{J}}=1.238896, c_{\mathrm{S}}=-1.646381, c_{\mathrm{U}}=2.115445$, $c_{\mathrm{N}}=2.061512$. The mass moment of Jupiter $\left(M_{11}=1\right)$, coupled with the modulation of the 11.862 year cycle by the further planets, plays the most important role in influencing the number of sunspots. Adopting the mass moment of Jupiter, $M_{\mathrm{J}}=1653.617$, as a unit, is generally equivalent to the statistical standardisation of the Wolf number. The approximate chronological sequence of the Wolf numbers in the years 1700-2001 may be obtained from the transformation: $W_{i}=W+w_{i} s$, where $W-$ is the arithmetical mean and $s-$ the standard variation.

The "concurrence" of the changes of standardised average consecutive Wolf numbers for 11-year cycles and average consecutive 11-year cycle values of the mass moment, $w_{i}=f\left(M_{i}\right)$ can be regarded as very interesting (Fig. 4).

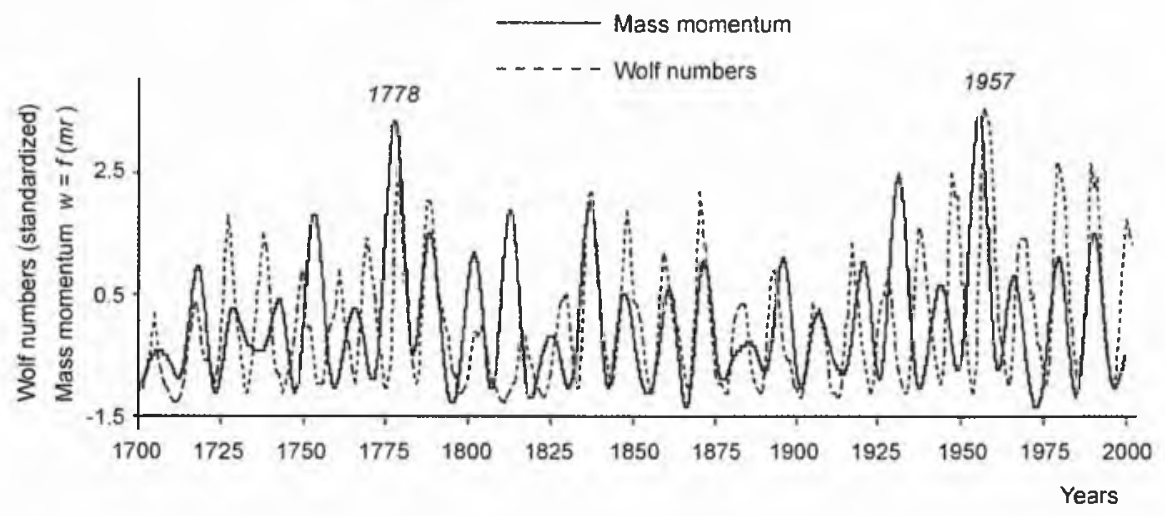

Fig. 5. Changes of the standardised Wolf numbers in 1779-2000 and the mass moment of the largest planets - using model (1): $w=f(M)$

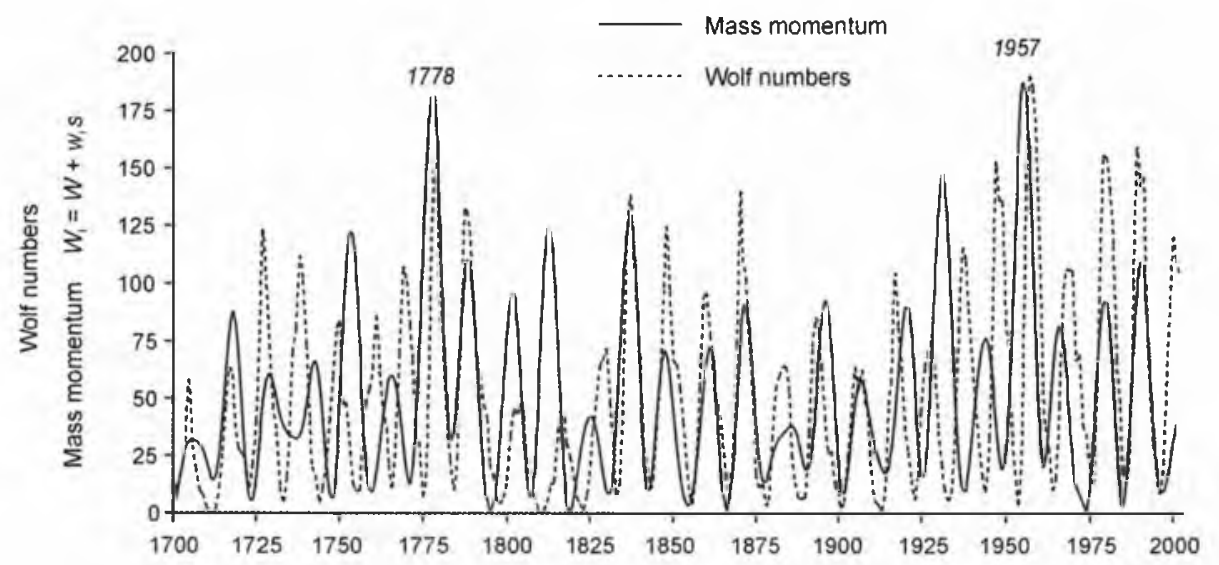

Fig. 6. Changes of the Wolf numbers in $1779-2000$ and a chart of the values obtained using the model (1): $w=f(M)$ - after the transformation $W_{f}=W+w_{i} s(W-$ arithmetic mean, $s-$ standard deviation) 
The comparison of the average annual values of the mass moment, i.e. the $w_{i}=f(M i)$ values, calculated using formula (1) and transformed: $W_{i}=W+w_{i}$, with the Wolf numbers is shown in Figures 5 and 6.

A relatively high conformity of the extreme values (minimums and maximums) of the mass moments in 1700-2001 with the observation series of the Wolf numbers (including the main maximums in the years 1778 and $1957-$ after the passage of the planetary period of 178.9 years) can be observed. Proof can be found of the impact of the four largest planets on the variability of solar activity (probably owing to the change of the Sun's acceleration in its movement in relation to the centre of the system's mass). A better approximation of the Wolf numbers in the years 1700-2001 is obtained by applying, in formula (1), the phase displacements: $c_{\mathrm{J}}=2.66701267, c_{\mathrm{s}}=-1.07882237$, $c_{U}=0.80431556, c_{N}=2.19098914$, determined using the "regression sinusoids" of the given Wolf numbers. The ecliptic co-ordinates of the planets were determined on the basis of Reznikov's formulas (1982). The demonstrated dependency of the solar activity on the location of the centre of the mass of the largest planets supports Butusov's hypothesis (1975) on the turbulence origin of sunspots, caused by the difference in the acceleration of the Sun's surface layers and its core.

The most recent major cooling in Europe occurred in the early $19^{\text {th }}$ century, during the three weakest, prolonged (12 or 13-year long) cycles of solar activity (1798-1833). This cooling occurred during the weakest, 13-year cycle of sunspots, from 1811 till 1823, during the absolute centennial minimum since 1700 .

With regard to the Solar System, 1811 was a unique year, as at that time the Sun's distance from the centre of the System's mass was the smallest (0.14 of the Sun's radius), and the Sun's acceleration was the highest (Boryczka, 1998).

\section{THE ROLE OF NORTH ATLANTIC OSCILLATION (NAO) IN DETERMINING THE CLIMATE IN EUROPE IN 1825-2000}

The tendencies concerning the air temperatures in Europe, which were revealed using simple regression equations $T=A_{0}+A t$ (direction coefficients $\mathrm{A}$ in ${ }^{\circ} \mathrm{C} / 100$ years), are presented in Table 1.

Table 1.

Tendencies in the air temperature change in selected European cities $\left({ }^{\circ} \mathrm{C} / 100\right.$ years)

\begin{tabular}{|lcccc|}
\hline \multicolumn{1}{|c}{ City } & Period & Winter & Summer & Year \\
Warsaw & $1779-1998$ & 1.12 & -0.06 & 0.58 \\
Prague & $1771-1990$ & 0.25 & -0.25 & -0.02 \\
Berlin & $1769-1990$ & 0.32 & -0.39 & 0.13 \\
Geneva & $1769-1980$ & 0.51 & -0.40 & 0.51 \\
Vienna & $1775-2002$ & 0.69 & -0.08 & 0.27 \\
Stockholm & $1756-1994$ & 0.86 & -0.08 & 0.46 \\
Copenhagen & $1768-1991$ & 0.94 & 0.05 & 0.55 \\
Moscow & $1779-2002$ & 1.65 & -0.15 & 0.68 \\
\hline
\end{tabular}




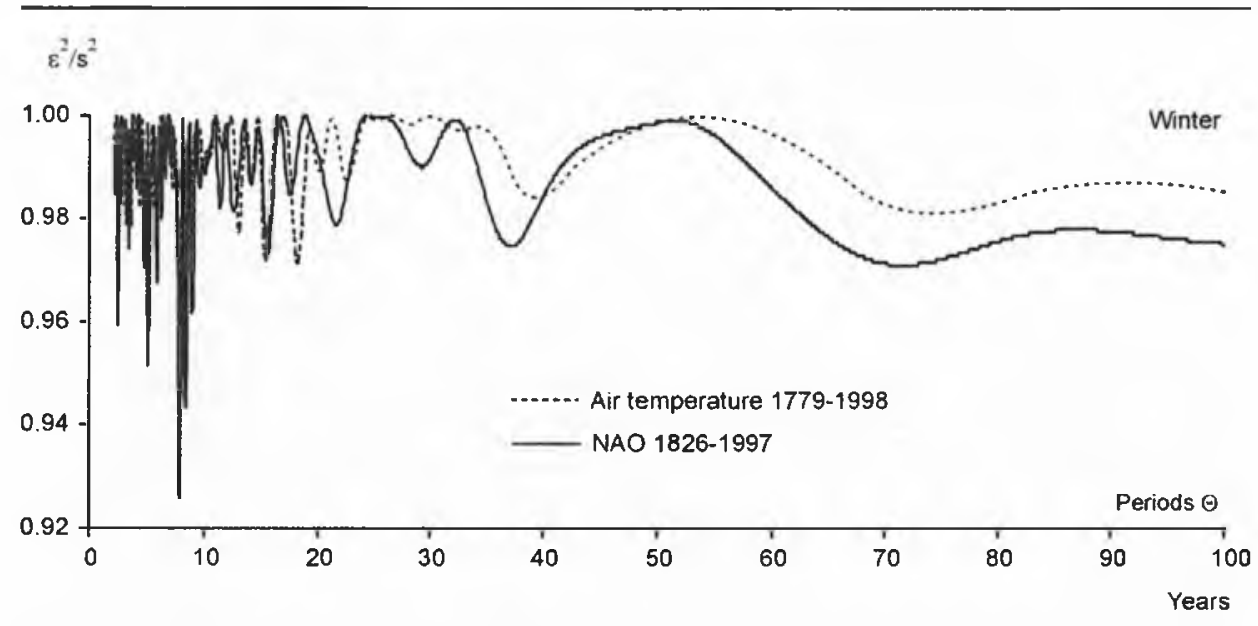

Fig. 7. Similar spectra of air temperature during winters in Warsaw $(T, 1780-1998)$ and the North Atlantic Circulation (NAO, 1826-1997) over the band of 2.0-100 years

As a rule, the tendency concerning the air temperature in European cities is growing in winter $(A>0)$ and falling in summer $(A<0)$. In Europe (and in Poland), winters are increasingly warmer. In other words, frosty winters are less frequent. For instance, in the years $1779-1998$ in Warsaw, winters were warmer by $1.1^{\circ} \mathrm{C}$ in a period of 100 lat, and summers were cooler by nearly $0.1^{\circ} \mathrm{C}$.

The thermal impact of the Atlantic Ocean water (warming in winter and cooling in summer) on the climate of Western and Central Europe (including Poland) is determined by the meridian gradient of atmospheric pressure - the zonal circulation.

The North Atlantic Oscillation (NAO) index, defined by Jones et al. (1997), was adopted as a measure of the zonal circulation. It is standardised difference in the pressure at the sea level between Gibraltar and south-western Iceland for the years 1825-1997.

It is interesting to compare the spectra: the air temperature during the winters in Warsaw in the years 1780-1998 and the NAO index for the years 1826-1997 over a period of 2-100 years (Fig. 7), determined using Boryczka's "regression sinusoid" method (1998). The spectra are characterised by a similar periodicity, with the dominant period of about 7.8 years. The similarity between the two spectra indicates that winters in Warsaw are shaped by periodic fluctuations of the NAO index (zonal circulation).

The tendencies concerning the NAO index are the following: decrease in the summer and increase in the winter. To put it differently, the latitudinal transport of air masses from the Atlantic Ocean eastwards is greater. The progressing warming, particularly in winter, is caused by an intensified warming impact of the Atlantic Ocean.

On the other hand, the small rising tendency of air temperature in summer is caused by the fading impact of the Atlantic Ocean on the climate in Poland. 


\section{SYNCHRONOUS CHANGES IN SOLAR RADIATION, PALEOTEMPERATURE AND $\mathrm{CO}_{2}$ CONCENTRATION IN THE ATMOSPHERE OVER THE LAST 400,000 YEARS}

The results of the measurements of carbon dioxide content and pealeotemperature over the past 160,000 years, revealed on the basis of chemical analysis of the ice core at the Vostok station, provide important information about the causes of the changes in the Earth's climate (The Atmosphere..., 1990). The global climate warming 135,000 years ago was accompanied by a sharp increase in the $\mathrm{CO}_{2}$ concentration in the atmosphere - similarly to the situation today; changes in the $\mathrm{CO}_{2}$ concentration and paleotemperature are synchronous. The maximum, dating back 135,000 years, is a natural warming of the Earth's climate caused by increased solar radiation. This is the maximum of the values of the sums of radiation at the latitude $\varphi=65^{\circ}$ between March and September, resulting from the changes in the Earth's orbit (Milankovič, 1938). The synchronicity of the changes in the sums of radiation, paleotemperature and $\mathrm{CO}_{2}$ concentration indicates that the carbon dioxide content in the atmosphere depends on the influx of solar radiation reaching the Earth's surface (temperature of the oceans' water). Currently, a sharp rising tendency concerning $\mathrm{CO}_{2}$ concentration is accompanied by a falling tendency concerning paleotemperature.

Similar conclusions can be drawn from a comparison of changes in the temperature $\left({ }^{\circ} \mathrm{C}\right)$ and carbon dioxide concentration in Antarctica over the last 400,000 years) (Petit et al., 1999), with the changes in the sums of solar radiation at latitude $\varphi=65^{\circ} \mathrm{N}$ between March and September (Fig. 8).

The dates of consecutive maximums of the sums of solar radiation at the latitude $\varphi=65^{\circ} \mathrm{N}$ in those months correspond to the dates of consecutive warming periods (the dates in italics denote the temperature maximums). In calculating the sums of solar radiation at the parallel $65^{\circ} \mathrm{N}$ from March to September, the following period lengths were adopted: 100,000 years, 40,000 years and 21,000 years. It turned out (Hays et al., 1976), that the isotope of oxygen ${ }^{18} \mathrm{O}$ in the deep-sea calcium carbonate deposits is characterised by the periodicity of: 100,000 years, 42,000 years and 23000 years.

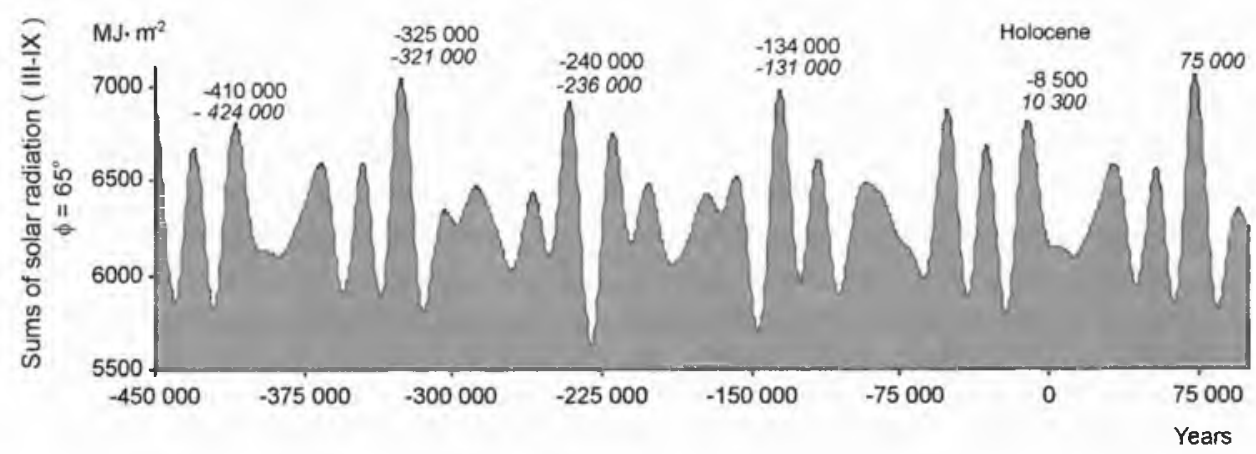

Fig. 8. Changes in the sums of solar radiation (in the period March-September) at the parallel $\varphi=65^{\circ} \mathrm{N}$ in the last 400,000 years, with a forecast up to 100,000 years 
According to the popular Milankovič theory, the four recent glaciations of the Earth (covering also Poland) were a result of the overlapping of three long cycles: 92,000 years - the Earth's eccentric orbit, 40,000 years - inclination of the Earth's axis to the orbit's surface and 21,000 years - the position of the perihelion with respect to the vernal equinox point. At that time, periodic changes in the parameters of the ecliptic orbit of the Earth caused a significant drop in solar radiation at high latitudes.

The synchronicity of changes in the sums of solar radiation reaching the Earth's surface $\left(\varphi=65^{\circ}\right)$, paleotemperature (determined on the basis of the isotope of oxygen $\mathrm{O}^{18}$ or hydrogen $\mathrm{H}^{2}$ content in the Antarctic ice) and $\mathrm{CO}_{2}$ concentration in the atmosphere invites the conclusion that the $\mathrm{CO}_{2}$ concentration in the atmosphere is higher in the years characterised by a greater influx of solar radiation reaching the Earth's surface. In other words, $\mathrm{CO}_{2}$ concentration in the atmosphere is higher when the oceans' water is warmer, that is, when the overall temperature is higher.

\section{REFERENCES}

Bernes C., 2003. A Warmer World. The Greenhouse Effect and Climate Change, Monitor 18, Swedish Environmental Protection Agency, SWE CLIM.

Bory czka J., 1998, Zmiany klimatu Ziemi (Changes of the Earth's Climate; in Polish)), Wyd. "Dialog", Warszawa.

B ory czka J., 2003. Trends in Climate Change in Europe and Their Causes. Man and Climate in the 20 th Century, (ed. J. L. Pyka et al.). Studia Geograficzne 75, Wyd. Uniw. Wrocl.

B utu s ow K. P., 1972, $K$ woprosu o tsiklitchnosti solniecznoi aktywnosti. Solntse, elektritchestvo zizni (On the Issue of the Periodicity of Solar Activity. Sun: Electricity of Life; in Russian), MGU, Moskwa.

Hays J. D., I mbrie J., Shacklet on N. J., 1976, Variation in the Earth's Orbit: Pacemaker of the Ice Ages, Science, 194, No. 4270.

IPCC (Intergovernmental Panel on Climate Change),1990, 1995.

Kondratiev K.J., Nikols ki G.A, 1970, Solar Radiation and Solar Activity. Quart. J. Royal. Meteor. Soc., No. 96.

Milankovič M., 1938, Matematitcheskaya klimatologiya i astronomitcheskaya teoriya kolebanii klimata (Mathematical Climatology and Astronomical Theory of Climate Fluctuations; in Russian), ONTU, Moskwa.

Petit J.R., Jouzel J., Rey naud D. et. al., 1999, Climate and Atmospheric History of the Past 420000 Years from the Vostok Ice Core, Antarctica, Nature 399.

The Atmosphere of the Planet Earth, 1990, WMO, No. 735.

English translation: Dorota Szmajda 